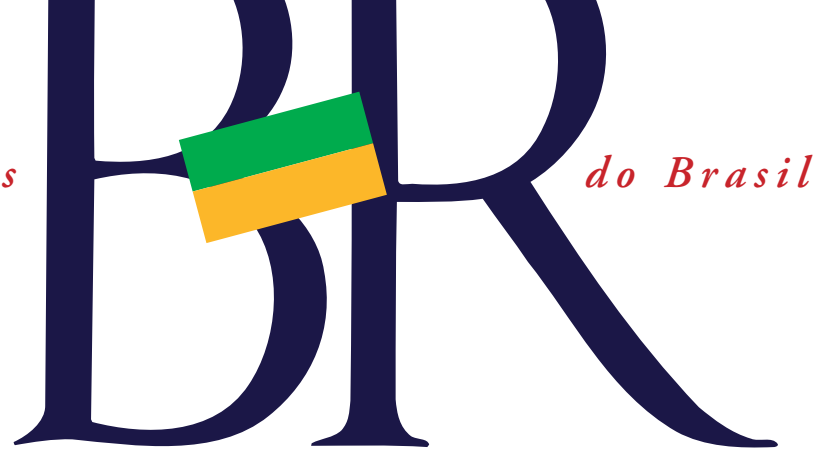

LEGISLAÇÃO AMBIENTAL

\section{Defender 0 ambiente é dever de todos}

O Brasil vive, atualmente, um momento de intensos debates no que diz respeito à legislação ambiental: uns afirmam que ela atrapalha a expansão da agricultura e condena muitos à miséria; outros afirmam que a agricultura destrói os recursos naturais nacionais e condena outros tantos à miséria; uns querendo impedir a circulação de pessoas em áreas urbanas consideradas de preservação permanente e de reserva legal; outros apontando que a ocupação de áreas de preservação em cidades é consequência natural da expansão urbana. Mais, recentemente chegou a constar da pauta do Congresso Nacional um projeto de lei que propunha a extinção da reserva legal nas propriedades rurais com o argumento de que "o papel de uma certa ecologia radical, fundamentalista e irracional é impedir nosso desenvolvimento".

LEGISLAÇÃo AMBIENTAL Existem três fases na história da proteção jurídica do ambiente no Brasil: a da exploração desregrada, quando não dispúnhamos de leis ambientais, mas ainda assim existiam, por exemplo, medidas de controle da extração de pau-brasil no período colonial; a fragmentária, no século XX, com os

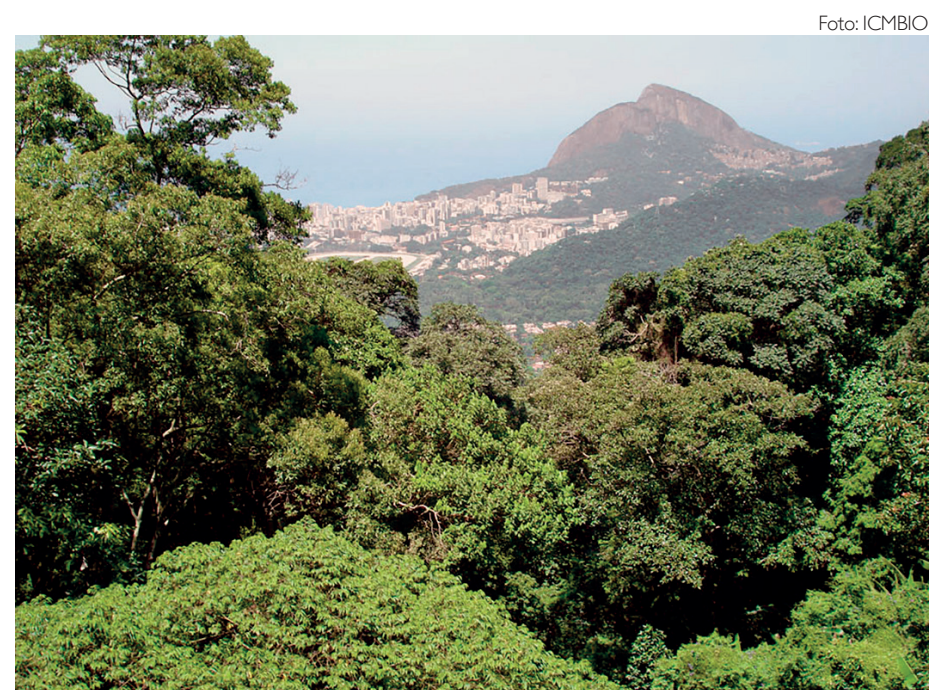

Áreas verdes, como o Parque Nacional da Tijuca (RJ), ajudam a controlar a poluição nas cidades

Códigos Florestais de 1934 e de 1965 e a Lei de Agrotóxicos, de 1989, por exemplo; e a fase dita holística, na qual o ambiente passa a ser protegido de maneira integral com a aprovação da Lei de Proteção da Vegetação Nativa (Lei 12.651/2012), conhecida como Novo Código Florestal.

José Antônio Aleixo da Silva, engenheiro agrônomo e professor titular da Universidade Federal Rural de Pernambuco (UFRPE), explica que o Código Florestal de 1934 (Decreto 23.793) "foi uma tentativa de combater os desmatamentos realizados para darem lugar a novos plantios de café e obrigava aos proprietários rurais manterem $25 \%$ da propriedade com cobertura florestal nativa”. Aleixo informa que Luciano Pereira da Silva, relator do anteprojeto desse código, alertava para as "dificuldades de implementação da lei, pois a maioria dos produtores rurais consideravam as árvores como empecilhos para a expansão da agropecuária, pois há mais de 400 anos a prática de desmatar não tinha o mínimo controle”. Na discussão do Novo Código Florestal, o embate entre as bancadas ruralista e ambientalista mobilizou o país. Aleixo, que é conselheiro da Sociedade Brasileira para o Progresso da Ciências (SBPC), afirma que "a disputa entre ruralistas e ambientalistas é permanente, embora existam vários trabalhos que mostrem que a produtividade agropecuária aumenta, principalmente no setor da pecuária, sem a necessidade de novos desmatamentos". Presidente da Academia Pernambucana de Ciências, Aleixo informa que a SBPC e a Academia Brasileira de Ciências criaram um grupo de trabalho composto por cientistas das diversas áreas ligadas à legis- 


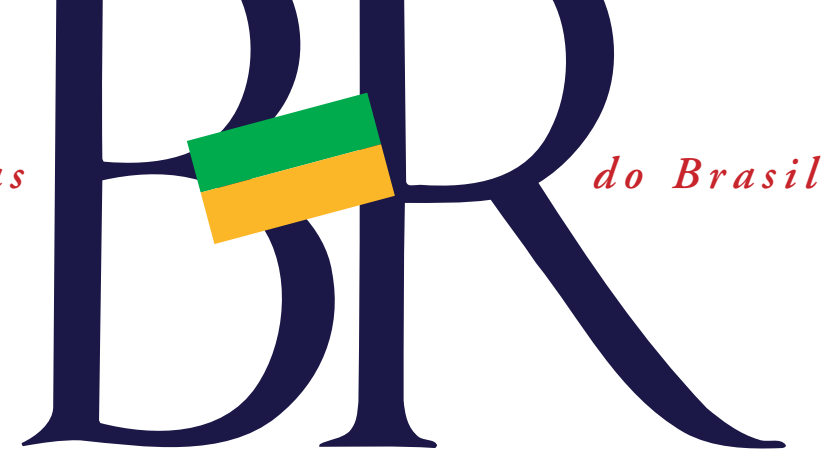

lação ambiental para elaborar uma proposta com informações qualificadas e com fundamentos científicos e tecnológicos, para dar subsídios aos congressistas na elaboração do Código Florestal. Esse trabalho deu origem ao livro O Código Florestal e a ciência: contribuiçôes para o diálogo, lançado em 2011, atualizado e republicado em português e em inglês durante a realização da Rio +20 , em 2012, e agraciado com o Prêmio Muriqui, como o documento mais completo sobre o Código Florestal brasileiro. Em artigo publicado na revista $\mathrm{Di}$ reito Ambiental e Sociedade (2018), a advogada Juliana Seawright Gonçalves considera que no direito ambiental adota-se a perspectiva de que o ambiente é a parte frágil, que deve ser objeto de proteção sempre, ante as arbitrariedades do Estado, da coletividade e dos indivíduos. Para Herman Benjamin, ministro do STJ e autor de vários trabalhos no tema, os recursos naturais são vistos como obstáculo à geração de riqueza e emprego, pois "quem não é capaz de valorizar e preservar a vida de sua própria espécie, certamente estará surdo à voz da razão que conclama à proteção dos outros seres vivos e das bases ecológicas", afirmou ele em artigo publicado em 2011 como parte do livro Direito constitucional ambiental brasileiro.

Mercedes Bustamante, bióloga e professora titular da Universidade de Brasília (UnB), afirma que a legis- lação ambiental brasileira não é um entrave para o crescimento sustentável da agricultura e da indústria, pois as atividades econômicas são dependentes da integridade e da saúde dos ecossistemas. Bustamante cita como exemplo a energia elétrica necessária na agricultura e na indústria: "a eletricidade éfornecida em grande parte por hidroeletricidade e o suprimento de água é dependente do papel dos ecossistemas naturais no ciclo hidrológico. A flexibilização da legislação ambiental é, portanto, um risco direto para a população brasileira".

\section{INTEGRAÇÃO NA CIDADE E NO CAMPO}

Áreas verdes protegidas constituem um seguro para a produção agrícola pois preservam polinizadores, recursos hídricos e são abrigo para inimigos naturais de pragas e doenças de plantas e animais. Nas cidades garantem controle de poluição, preservam encostas, evitando deslizamentos, e impedem a formação de ilhas de calor, entre outros. Bustamante, que é membro titular da Academia Brasileira de Ciências, enfatiza que "o setor produtivo é dependente de mão de obra e a saúde ambiental tem uma relação direta com a saúde humana, pois reduz o absenteísmo provocado por enfermidades associadas à qualidade do ar e da água", disse.

A proteção de recursos hídricos em área urbana, com margens vegetadas e preservação de remanescentes de

\section{PARECEM IGUAIS, MAS SÃO DIFERENTES}

Reserva legal $(\mathrm{RL})$ : em área rural; pode ser explorada com o manejo sustentável, desde que assegure o uso econômico sustentável dos recursos naturais do imóvel rural, auxilie a conservação e a reabilitação dos processos ecológicos e promova a conservação da biodiversidade, bem como o abrigo e a proteção de fauna silvestre e da flora nativa. 0 porcentual a ser preservado varia conforme a localização do imóvel rural: $80 \%$ em área de floresta; 35\% em áreas de Cerrado; e $20 \%$ nas demais regiões.

Área de preservação permanente (APP): em área rural ou urbana; coberta ou não por vegetação nativa, com função de preservar a paisagem, os recursos hídricos, os solos, a estabilidade geológica e a biodiversidade, facilitando o fluxo gênico de fauna e flora. Não pode ser explorada economicamente e a supressão de vegetação só pode ocorrer sob autorização do poder público local, quando for de utilidade pública, de interesse social e de baixo impacto. 


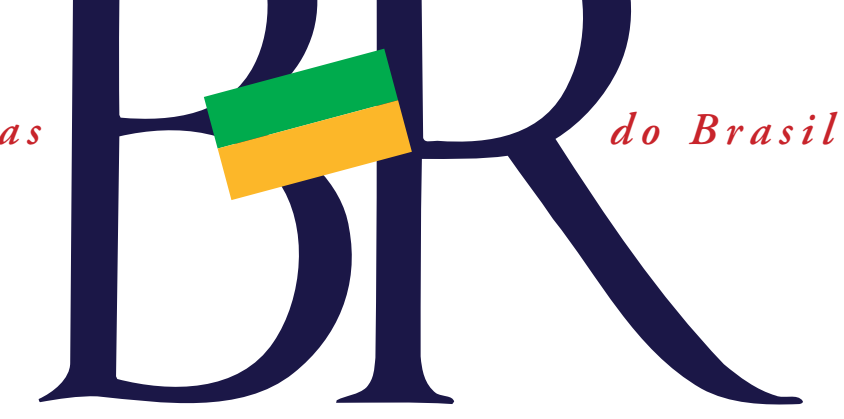

vegetação, é recente. Os primeiros esforços de preservação ambiental das cidades se deu no início do século XX, visando controle de doenças. Marcela Cury Petenusci, arquiteta e urbanista, explica que área de preservação permanente (APP) em área urbana tem pouco valor agregado: "em cidades de porte médio ou grande, que atraem pessoas procurando emprego, as APPs são ocupadas porque são menos valorizadas. Tem-se um problema duplo: a população migrante ocupa uma área frágil e tem dificuldade de acesso à moradia de qualidade". Coautora do livro Seis passos para a cidade humana, organizado no Instituto Paulista de Cidades Criativas e Identidades Culturais (IPCCIC), Petenusci considera que a discussão de políticas ambientais não pode estar dissociada da discussão de políticas econômicas e sociais: "não dá para pensar em planejamento urbano sem pensar em programas que permitam que a população tenha acesso à qualidade de vida”. Segundo ela, é fundamental que se pense a cidade como um sistema, "considerando de forma associada e agregada valores ambientais, sociais, econômicos, territoriais e culturais, para que se possa mudar o desenho de cidades", coloca Petenusci.

No Brasil, várias cidades respeitam o ambiente em algumas áreas, geralmente no centro ou próximas a este. Um exemplo é Curitiba, no
Paraná, cujo plano diretor, de 1972, tornou-se uma referência em urbanismo ao criar corredores verdes e sistemas de parques protegendo as margens dos principais cursos d'água. Mas em muitas cidades, no centro existem áreas verdes e parques e na periferia ocorre uma ocupação irregular. Petenusci cita como exemplo Ribeirão Preto, no interior de São Paulo, que no final do século XX passou a ser considerada a "Califórnia brasileira" e tornou-se destino de uma importante onda migratória: "muitas áreas verdes da periferia foram ocupadas por favelas". Para ela, existem muitos planos e políticas nos quais constam propostas ambientais, "mas a consolidação de ações exige monitoramento, acompanhamento e fiscalização, que estão vinculados à gestão muito mais do que ao planejamento".

José Felipe Ribeiro, biólogo e pesquisador da Embrapa Cerrados, coloca que existem inúmeras pesquisas em agropecuária que apontam que a diversificação de culturas e de atividades, a recuperação e manejo de pastagens, restauração da vegetação em reserva legal (RL) e APP e sistemas de integração (lavoura-pecuária, lavoura-floresta, pecuária-floresta e lavoura-pecuária-floresta) geram renda para o produtor rural e trazem menor risco à produção agrícola.

Áreas protegidas exercem um papel fundamental de conectividade, tanto nas cidades quanto em áreas rurais.
Professora do Centro Moura Lacerda e da Universidade de Ribeirão Preto, Petenusci considera que as áreas protegidas nas cidades devem ser vistas como espaço da comunidade, corredores verdes para fauna, para pedestres e para ciclistas. Nas áreas rurais, Ribeiro aponta que é essencial o comprometimento da sociedade e do agricultor no processo de manutenção e recuperação dos ambientes naturais. E acrescenta: "o sucesso de estratégias de recuperação e de preservação depende de um diagnóstico das propriedades e da percepção dos proprietários que a qualidade e o rendimento na produção agrícola dependem da APP e da RL”.

ENCARANDO A REALIDADE Vivemos em um mundo altamente conectado em que os mercados consumidores estão atentos não somente à qualidade dos produtos que consomem, mas também à qualidade dos processos produtivos. "A ciência do sistema terrestre tem demonstrado os potenciais impactos de conversão de larga escala de ecossistemas nativos para o funcionamento biogeoquímico da Terra e para a conservação da biodiversidade", destaca Bustamante, que em 2018 recebeu a Comenda da Ordem Nacional do Mérito Científico. "O Brasil assinou acordos internacionais nos quais assumiu compromissos de conservação. Precisamos avaliar o risco de perda de credibilidade internacional 


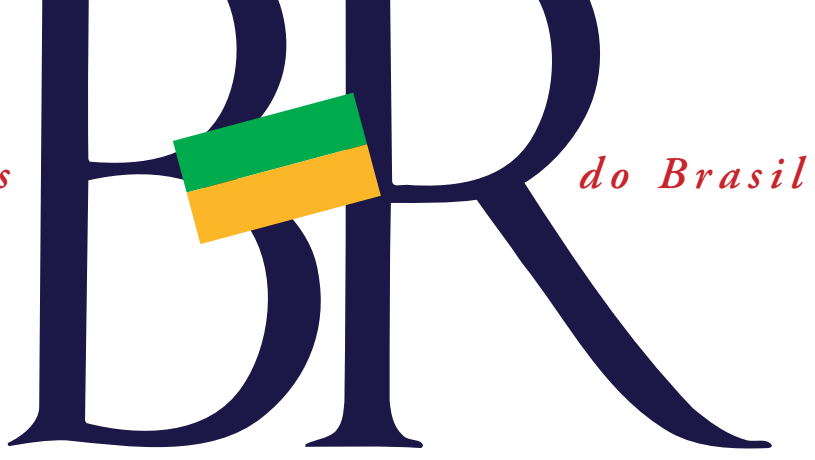

frente a benefícios de curto-prazo e para somente alguns setores da sociedade brasileira", disse.

Rico em recursos naturais, o Brasil possui uma das mais elevadas biodiversidades do mundo. Mas "agimos como se isso fosse uma maldição, algo que temos que superar, ultrapassar, destruir para atingir uma espécie de paraíso do desenvolvimento", avalia Nurit Bensusam, bióloga e autora do blog Planeta bárbaro e colaboradora do Instituto SocioAmbiental (ISA). "No Brasil muitos se recusam a imaginar que é possível outra forma de avanço, respeitando o ambiente e transformando seus recursos em novas oportunidades de desenvolvimento, de modo criativo e inclusivo. Ignoramos, quase de propósito, as ligações entre a integridade ambiental e a disponibilidade e qualidade da água, a fertilidade dos solos, o controle de pragas e doenças, entre muitos outros serviços ambientais prestados pela natureza", afirma. Para ela, "com a crise climática batendo às nossas portas, não será possível mais fingir não ver essas relaçóes e escapar impunemente. Não se trata sequer de garantir a sobrevivência das futuras gerações, se trata de assegurar a possibilidade de viver, aqui, num mundo pior - mais quente, com mais eventos extremos, com menos água - mas ainda assim poder viver".

Leonor Assad

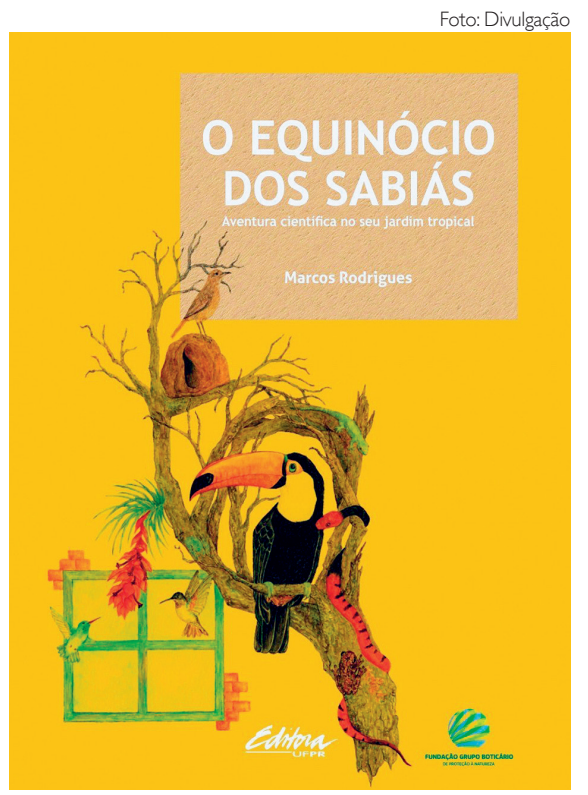

A ciência em um jardim urbano

\section{RESENHA}

\section{A indelével beleza do jardim tropical}

Marcos Rodrigues, estudioso de aves da Universidade Federal de Minas Gerais (UFMG), em seu livro O equinócio dos sabiás: aventura científica no seu jardim tropical (Editora UFPR, 2018), abre as portas do seu jardim de $1.500 \mathrm{~m}^{2}$, situado na cidade de Lagoa Santa, na região metropolitana de Belo Horizonte. Nesse cenário, ponto de encontro entre dois importantes biomas brasileiros, a Mata Atlântica e o Cerrado, Rodrigues encontra a fonte de inspiração para retratar de forma leve temas caros à disciplina de ecologia. Ao longo do ano, a passagem gradual e silenciosa das quatro estações marca as 41 crônicas do livro, ora em forma de diário, ora de manual de "observação, contemplação e iluminação (no sentido de gerar ideias)". 0 autor nos convida a uma jornada de exploração dos nossos quatro sentidos - visão, olfato, paladar e tato - pela exuberante natureza ao nosso redor.

Mesmo nos centros urbanos é possível admirar a floração intensa de ipês e flamboyants; escutar o canto de pássaros, a revoada de maritacas ou a algazarra de cigarras no entardecer; saborear frutas colhidas diretamente de uma mangueira ou jabuticabeira; e sentir na pele os raios de sol delicados do outono ou a secura do inverno. No amplo quintal do autor, a vegetação de espécies nativas e exóticas abriga uma enorme diversidade de fauna, desde os temidos insetos (como cupins e lagartas) até as mais belas aves, como tucanos, beija-flores e os sabiás, pássaros dispersores de sementes em áreas degradadas e urbanas. No final das contas é o canto dos sabiás que nos chama a observar os movimentos e a dinâmica da natureza. Com eles podemos aprender a preservar a nossa biodiversidade. 